\section{Comparison of Extractants for Calibrating Phosphorus Application Rates in a Calcareous Soil}

\author{
Qiang Zhu' \\ College of Resources and Environment, Huazhong Agricultural University, \\ Wuhan, Hubei Province 430070, China
}

Yuncong C. Li

Tropical Research and Education Center, Institute of Food and Agricultural Sciences, University of Florida, Homestead, FL 33031

Rao S. Mylavarapu

Soil and Water Sciences Department, University of Florida, Gainesville, FL 32611

\author{
Kelly Morgan \\ Southwest Florida Research and Education Center, Institute of Food and \\ Agricultural Sciences, University of Florida, Immokalee, FL 34142
}

\section{Mingjian Geng \\ College of Resources and Environment, Huazhong Agricultural University, Wuhan, Hubei Province 430070, China}

Additional index words. tomato production, multiple regression model, change point, phosphorus index

\begin{abstract}
Preplant soil testing is essential for optimizing phosphorus (P) fertilization and minimizing the potential for soil $P$ losses. Currently, there is no effective soil $P$ extractant for calcareous soils in Florida. This study was conducted to compare Mehlich-3, ammonium bicarbonate-diethylenetriaminepentaacetic acid (AB-DTPA), and Olsen for evaluating $P$ availability, estimating soil-test $P$ (STP) critical levels, and calibrating $P$ application rates for fresh-market tomato (Solanum lycopersicum $L$.) production in a calcareous soil. Tomatoes were grown during Winter 2014 and 2015 with $P$ application rates of $0,29,49,78,98$, and $118 \mathrm{~kg} \cdot \mathrm{ha}^{-1} P$. Water-extractable $P$ (water-P) and dissolved reactive $P$ (DRP) in leachate were used to determine the STP change point of leaching potential. Results showed the greatest correlation occurred between Mehlich-3 and Olsen of the three STP extractants. For Mehlich-3-P, the medium STP level (producing $75 \%$ to $90 \%$ relative yield) was predicted from 76 to $89 \mathrm{mg} \cdot \mathrm{kg}^{-1}$ and the change point was predicted at 88 or $104 \mathrm{mg} \cdot \mathrm{kg}^{-1}$ by split-line models. The $P$ requirement was calculated from 52 to $112 \mathrm{~kg} \cdot \mathrm{ha}^{-1}$ when Mehlich-3-P was rated as low level (producing $50 \%$ to $75 \%$ relative yield), which was from 42 to $76 \mathrm{mg} \cdot \mathrm{kg}^{-1}$. The multiple regression models using AB-DTPA-P and Olsen-P could not predict either the medium STP level or the practical $P$ application rates for the low level. Consequently, based on 2 years of data, Mehlich-3 was the most effective extractant for estimating soil $P$ availability and calibrating $P$ rates in calcareous soils with an extremely high calcium carbonate $\left(\mathrm{CaCO}_{3}\right)$ content.
\end{abstract}

There are $\approx 12,000$ ha of calcareous soils dedicated to vegetable production in South Florida (U.S. Department of Agriculture, 2014). After fertilizer application, $P$ can be

Received for publication 3 Dec. 2018. Accepted for publication 19 Mar. 2019

This research was funded by Florida Department of Agriculture and Consumer Services (FDACS) and the Fundamental Research Funds for the Central Universities (Program No. 2662019QD016).

We are grateful to Guiqin $\mathrm{Yu}$ and Jose Castillo, University of Florida/Tropical Research and Education Center, for their help in crop management and data collection

${ }^{1}$ Corresponding author. E-mail: zhuqiang@mail. hzau.edu.cn.
Code, 2017). Thus, preplant soil testing, which is performed to evaluate soil-P availability, is essential for optimum crop production and protection of the Biscayne Aquifer in South Florida.

The most commonly used STP extractants for calcareous soils include Olsen, ABDTPA, and Mehlich-3. The Olsen or sodium bicarbonate extraction method uses bicarbonate $\left(\mathrm{HCO}_{3}^{-}\right)$and hydroxide $\left(\mathrm{OH}^{-}\right)$anions to extract labile $\mathrm{P}$ into solution (Olsen et al., 1954). AB-DTPA is a multielement extractant used in areas with calcareous soils (Soltanpour and Schwab, 1977). Similar to the Olsen method, the $\mathrm{HCO}_{3}{ }^{-}$in AB-DTPA serves to enhance phosphate solubility. Mehlich-3 was developed for extracting $\mathrm{P}$ and other macronutrients and micronutrients from a wide range of soils (Mehlich, 1984). The Mehlich-3 solution extracts $\mathrm{P}$ by dilute acid and fluoride $\left(\mathrm{F}^{-}\right)$, and acetic acid buffers the solution $\mathrm{pH}$ at 2.5 to prevent neutralization in calcareous soil (Wang et al., 2004). Rashid et al. (1999) observed significant correlations between $\mathrm{P}$ uptake by greenhouse-grown mung bean (Vigna radiata) and STP by Olsen, AB-DTPA, and Mehlich-3 in a calcareous soil. In our previous study, P uptake by snap bean (Phaseolus vulgaris) also correlated significantly with soil-P extracted by both AB-DTPA and Mehlich-3 (Zhu et al., 2016).

In addition to agronomic evaluation, STP was used to estimate $\mathrm{P}$ loss potential to water sources (McDowell et al., 2001; Sims et al., 2002). A split-line model was introduced to describe the relationship between STP and water- or calcium chloride-extractable $\mathrm{P}$ or DRP in leachate (McDowell et al., 2001). In the model, the intersection of the two lines is defined as a change point, which is a soil-P concentration above which soil $\mathrm{P}$ has a greater potential to be released to water. The rapid increase of $\mathrm{P}$ loss potential after the change point can be attributed to the saturation of soil-P fixing sites as STP concentration increases (McDowell and Sharpley, 2001). The values of change points depend on soil properties and management practices (Hesketh and Brookes, 2000; McDowell et al., 2001). An optimum STP concentration should be sufficient for crop production and should be less than the change point (Bai et al., 2013). For a more comprehensive risk assessment, a $P$ index, which combines STP with site characteristics and P management practices, was developed to assess the potential of $\mathrm{P}$ losses from agricultural areas to water bodies (Lemunyon and Gilbert, 1993).

The STP interpretations using Mehlich-3 have been established for vegetables grown on acid-mineral soils in Florida (Freeman et al., 2014b). In calcareous soils, however, AB-DTPA was adopted and $10 \mathrm{mg} \cdot \mathrm{kg}^{-1}$ was proposed to be the critical level for vegetable production without calibrated interpretations ( $\mathrm{Li}$ et al., 2000). Because no soil-test calibration has been performed in Floridian calcareous soils under field conditions, the STP interpretations and $\mathrm{P}$ recommendations are not available. Therefore, the objectives of this study were to compare three 
extractants-Mehlich-3, AB-DTPA, and Olsen - in 1) estimating $P$ availability with different $\mathrm{P}$ application rates, 2) establishing STP critical level, and 3) calibrating the P requirement for tomato production on a calcareous soil.

\section{Materials and Methods}

A 2-year field trial, during Winter 2014 (29 Oct. 2014-24 Mar. 2015) and Winter 2015 (15 Oct. 2015-16 Feb. 2016), was conducted at the University of Florida/ Tropical Research and Education Center, Homestead, FL. The seasonal average $10-\mathrm{cm}$ soil temperatures were 22.9 and $23.7^{\circ} \mathrm{C}$, and the total rainfall accumulations were 130 and $564 \mathrm{~mm}$ in 2014 and 2015, respectively. Soil (Loamy-skeletal, carbonatic, hypothermic Lithic Udorthents) physical and chemical characteristics before applying fertilizers in the growing season of 2014 were gravel (>2 mm), $632 \mathrm{~g} \cdot \mathrm{kg}^{-1}$; clay, $31 \mathrm{~g} \cdot \mathrm{kg}^{-1}$; silt, $49 \mathrm{~g} \cdot \mathrm{kg}^{-1}$; sand, $288 \mathrm{~g} \cdot \mathrm{kg}^{-1} ; \mathrm{pH}, 7.8$; equivalent carbonate concentration, $379 \mathrm{~g} \cdot \mathrm{kg}^{-1}$; organic matter, $57 \mathrm{~g} \cdot \mathrm{kg}^{-1}$; nitrate-nitrogen, $22 \mathrm{mg} \cdot \mathrm{kg}^{-1}$; ammonium-nitrogen, $7 \mathrm{mg} \cdot \mathrm{kg}^{-1}$; AB-DTPA extracted potassium (K), 82 $\mathrm{mg} \cdot \mathrm{kg}^{-1}$; and total $\mathrm{P}, 1473 \mathrm{mg} \cdot \mathrm{kg}^{-1}$. P application rates included $0,29,49,78,98$, and $118 \mathrm{~kg} \cdot \mathrm{ha}^{-1} \mathrm{P}$. Every P rate was replicated three times with a randomized complete block design. Each plot was $9.1 \mathrm{~m}$ long and included three beds, which were $20 \mathrm{~cm}$ high, $91 \mathrm{~cm}$ wide, and covered with polyethylene mulch. Treatments were set on the same plots during the two growing seasons. Total season nitrogen $(\mathrm{N})$ and $\mathrm{K}$ were applied at the same rates for all treatments with $224 \mathrm{~kg} \cdot \mathrm{ha}^{-1} \mathrm{~N}$ and $149 \mathrm{~kg} \cdot \mathrm{ha}^{-1} \mathrm{~K}$. All the P, $56 \mathrm{~kg} \cdot \mathrm{ha}^{-1} \mathrm{~N}$, and $56 \mathrm{~kg} \cdot \mathrm{ha}^{-1} \mathrm{~K}$ were applied $8 \mathrm{~d}$ before transplanting with triple superphosphate, urea, and potassium sulfate, respectively. These dry fertilizers were banded on the bed surface with two strips and $15 \mathrm{~cm}$ away from the bed center, where tomatoes were planted, then incorporated into the soil to an $8-\mathrm{cm}$ depth. The residual $\mathrm{N}$ and $\mathrm{K}$ were supplied weekly through drip fertigation. Tomato seedlings (cv. Ridgerunner; Syngenta, Greensboro, NC) were transplanted in the bed center on 6 Nov. 2014 and 23 Oct. 2015, with a population of 11,960 plants/ ha. Pest control and drip irrigation management followed the recommendations from the University of Florida/Institute of Food and Agricultural Sciences (Freeman et al., 2014a).

Soil samples were collected $0,40,70$, 105 , and $145 \mathrm{~d}$ after preplant fertilization
(DAPF) in 2014; and 0, 30, 60, 90, and 120 DAPF in 2015 [i.e., preplant, first flowering, early fruit setting, first harvest (FH), and final harvest stages]. The 0 DAPF indicated the soil sampling date before applying fertilizers. Three subsamples, which were collected using an auger with a $3-\mathrm{cm}$ diameter from a depth of 0 to $20 \mathrm{~cm}$ in one bed of each plot, composed one soil sample. The soil sampling spots were selected at around 2-m intervals and $10 \mathrm{~cm}$ away from the tomato plants. From the plots with $\mathrm{P}$ rates of $0,29,78$, and $118 \mathrm{~kg} \cdot \mathrm{ha}^{-1}$, leachate was captured cumulatively by gravitational lysimeter $(28-\mathrm{cm}$ internal diameter by $61-\mathrm{cm}$ depth) buried $20 \mathrm{~cm}$ under the soil surface. The leachate samples were collected $39,74,94$, and 138 DAPF in 2014; and 30, 63, 93, and 122 DAPF in 2015. Soil $\mathrm{P}$ was extracted by Mehlich-3 [solution $\mathrm{pH}, 2.5$; soil:solution ratio, 1:10 (Mehlich, 1984)], AB-DTPA [solution $\mathrm{pH}, 7.6$; soil: solution ratio, 1:2 (Soltanpour and Schwab, 1977)], Olsen [solution $\mathrm{pH}, 8.5$; soil:solution ratio, 1:20 (Olsen et al., 1954)], and distilled water [soil:solution ratio, 1:10 (Korndorfer et al., 1995)]. The $\mathrm{P}$ concentration in the extract and the DRP concentration in the leachate were analyzed by the ascorbic acid-molybdenum blue method using a spectrophotometer (DU 640; Beckman Instruments Inc., Fullerton, CA) (Murphy and Riley, 1962). At every analytical step, quality control blanks were conducted according to standard techniques. The DRP load was the result of multiplying leachate DRP concentration by the leachate volume. Tomato fruits were harvested 119,133 , and 146 DAPF in 2014; and 96, 110, and 124 DAPF in 2015 as the first, second, and third harvest, respectively. Relative yield was calculated by dividing the actual yield of each replication by the maximum yield among all the plots in each season (Zhu et al., 2017b).

The GLM procedure in the SAS program (version 9.2; SAS Institute Inc., Cary, NC) and Duncan's multiple range test (when the $P$ value of the analysis of variance was less than 0.05 ) were used to compare the means of STP within each extractant and tomato marketable yield for each growing season. Simple linear and split-line models in SigmaPlot (version 14.0; Systat Software Inc., San Jose, CA) were used to evaluate the correlations among extractants and the relationship between STP and leachate DRP. Every replicate from the two growing seasons was used in the models. To correlate with STP, the leachate DRP collected 24 to 39 d later than the related soil sampling dates were used, whereas at 39 DAPF in 2014 and 30 DAPF in 2015 only the leachate DRP from the treatment without $P$ fertilization was included. The better fit model was selected based on $P<0.05$ and a greater coefficient of determination $\left(r^{2}\right)$.

A multiple regression model [Relative yield $=\mathrm{a}+(\mathrm{b} \times \mathrm{STP})+(\mathrm{c} \times \mathrm{P}$ rate $)+(\mathrm{d} \times$ $\left.\mathrm{STP}^{2}\right)+\left(\mathrm{e} \times \mathrm{P}_{\text {rate }^{2}}\right)+(\mathrm{f} \times \mathrm{STP} \times \mathrm{P}$ rate $\left.)\right]$ was carried out to calibrate $\mathrm{P}$ rates (Slaton et al., 2009; Zhu et al., 2017b). The 50\%, 75\%, and $90 \%$ relative yield were chosen to calculate STP critical levels (i.e., very low, low, medium, and high STP levels indicated $<50 \%, 50 \%$ to $75 \%, 75 \%$ to $90 \%$, and $>90 \%$ relative yield could be expected, respectively, without $\mathrm{P}$ addition) and required $\mathrm{P}$ rates (Savoy, 2013). When calculating the $P$ index, the rating value of each parameter was adopted based on the work of Hurt et al. (2013), and 150 was considered the environmental threshold of the P index (Table 1).

\section{Results}

Tomato marketable yields of $\mathrm{FH}$ accounted for $47 \%$ to $66 \%$ and $13 \%$ to $54 \%$ of the total season harvest (TSH) yields in 2014 and 2015 , respectively (Table 2). In 2014, P rates $\geq 78 \mathrm{~kg} \cdot \mathrm{ha}^{-1}$ resulted in significantly greater FH marketable yields than those with rates less than $49 \mathrm{~kg} \cdot \mathrm{ha}^{-1}$. However, no significant differences were found in the marketable yields of the first and second combined harvest (FSH) and TSH in 2014. Significantly greater marketable yields were observed in both $\mathrm{FH}$ and FSH with $\mathrm{P}$ rates $\geq 49 \mathrm{~kg} \cdot \mathrm{ha}^{-1}$ in 2015. A P rate of $78 \mathrm{~kg} \cdot \mathrm{ha}^{-1}$ resulted in the greatest marketable yield in TSH of 2015 . The marketable yields from FH in 2014 and FSH in 2015 were used to calculate relative yield in each season.

Preplant STP concentrations (at 0 DAPF) in 2015 were not significantly affected by $\mathrm{P}$ rates applied in 2014 (Table 2). The STP concentrations at 0 DAPF in 2015, averaging from all $\mathrm{P}$ rates, increased by $40 \%$ for Mehlich-3-P and decreased by $13 \%$ and $10 \%$ for AB-DTPA-P and Olsen-P, respectively, compared with those values in 2014 . Combining all the STP concentrations throughout the two seasons, significant correlations were found among Mehlich-3-P, AB-DTPA-P, and Olsen-P (Fig. 1). The correlation between Mehlich-3-P and Olsen$\mathrm{P}$ was predicted by a split-line model. When Mehlich-3-P was greater than $99 \mathrm{mg} \cdot \mathrm{kg}^{-1}$, the slope of the correlation line declined significantly from 2.1 to 0.45 (correlation equation changed from $y=2.1 x+9.1$ to $y=0.45 x+$ 80.1). A similar correlation occurred between Mehlich-3-P and AB-DTPA-P.

Table 1. Calculation of phosphorus (P) index in Miami-Dade County, FL, based on Hurt et al. (2013).

\begin{tabular}{|c|c|c|c|}
\hline \multicolumn{2}{|c|}{ Part A } & \multicolumn{2}{|c|}{ Part B } \\
\hline Site and transport characteristics & Rating value & $\mathrm{P}$ source management & Rating value \\
\hline Soil erosion & 1 & Soil fertility index & Mehlich-3-P $\left(\mathrm{mg} \cdot \mathrm{kg}^{-1}\right) \times 2 \times 0.025$ \\
\hline Runoff potential & 2 & $\mathrm{P}$ application rate & $\mathrm{kg} \cdot \mathrm{ha}^{-1} \times 0.103$ \\
\hline Leaching potential & 8 & Application method & 0 \\
\hline Potential to reach water body & 0 & Waste water application & 0 \\
\hline Total & 11 & Total & - \\
\hline
\end{tabular}

$\mathrm{P}$ index $=$ Total for part $\mathrm{A} \times$ Total for part $\mathrm{B}$. 
Table 2. Preplant soil-test phosphorus (P) concentrations extracted by Mehlich-3, ammonium bicarbonate-diethylenetriaminepentaacetic acid (AB-DTPA), and Olsen, and tomato marketable yields in the first harvest (FH), first and second combined harvest (FSH), and total season harvest (TSH) as affected by $\mathrm{P}$ fertilizer application rates in 2014 and 2015.

\begin{tabular}{|c|c|c|c|c|c|c|}
\hline \multirow[b]{2}{*}{$\mathrm{P}$ rate $\left(\mathrm{kg} \cdot \mathrm{ha}^{-1}\right)$} & \multicolumn{3}{|c|}{ Preplant soil-test $\mathrm{P}\left(\mathrm{mg} \cdot \mathrm{kg}^{-1}\right)$} & \multicolumn{3}{|c|}{ Yield (t.hat $\left.{ }^{-1}\right)$} \\
\hline & Mehlich-3 & AB-DTPA & Olsen & FH & FSH & TSH \\
\hline 0 & 32.8 & 13.0 & 20.0 & $38.3^{\mathrm{z}} \mathrm{c}$ & 64.1 & 74.3 \\
\hline 78 & 32.8 & 13.0 & 20.0 & $50.1 \mathrm{ab}$ & 69.2 & 76.3 \\
\hline 98 & 39.5 & 15.7 & 20.0 & $51.2 \mathrm{ab}$ & 74.7 & 82.6 \\
\hline 118 & 37.7 & 15.5 & 21.4 & $60.0 \mathrm{a}$ & 87.2 & 97.1 \\
\hline 0 & 42.7 & 10.8 & 15.0 & $3.9 \mathrm{~b}$ & $13.4 \mathrm{~b}$ & $31.2 \mathrm{~b}$ \\
\hline 29 & 43.6 & 10.8 & 15.8 & $5.8 \mathrm{~b}$ & $15.1 \mathrm{~b}$ & $32.2 \mathrm{~b}$ \\
\hline 49 & 56.4 & 13.8 & 18.3 & $17.9 \mathrm{a}$ & $24.4 \mathrm{a}$ & $33.6 \mathrm{~b}$ \\
\hline 78 & 53.2 & 13.3 & 20.4 & $16.0 \mathrm{a}$ & $25.7 \mathrm{a}$ & $39.8 \mathrm{a}$ \\
\hline 98 & 52.3 & 13.1 & 20.2 & $18.6 \mathrm{a}$ & $26.0 \mathrm{a}$ & $34.7 \mathrm{~b}$ \\
\hline 118 & 60.1 & 15.3 & 21.3 & $17.7 \mathrm{a}$ & $25.1 \mathrm{a}$ & $34.3 \mathrm{~b}$ \\
\hline$P$ value & 0.34 & 0.23 & 0.17 & 0.001 & 0.001 & 0.03 \\
\hline
\end{tabular}

${ }^{\mathrm{z}}$ Means within each column followed by different letters are significantly different at the $5 \%$ level.

${ }^{\mathrm{y}} P$ value of the analysis of variance.
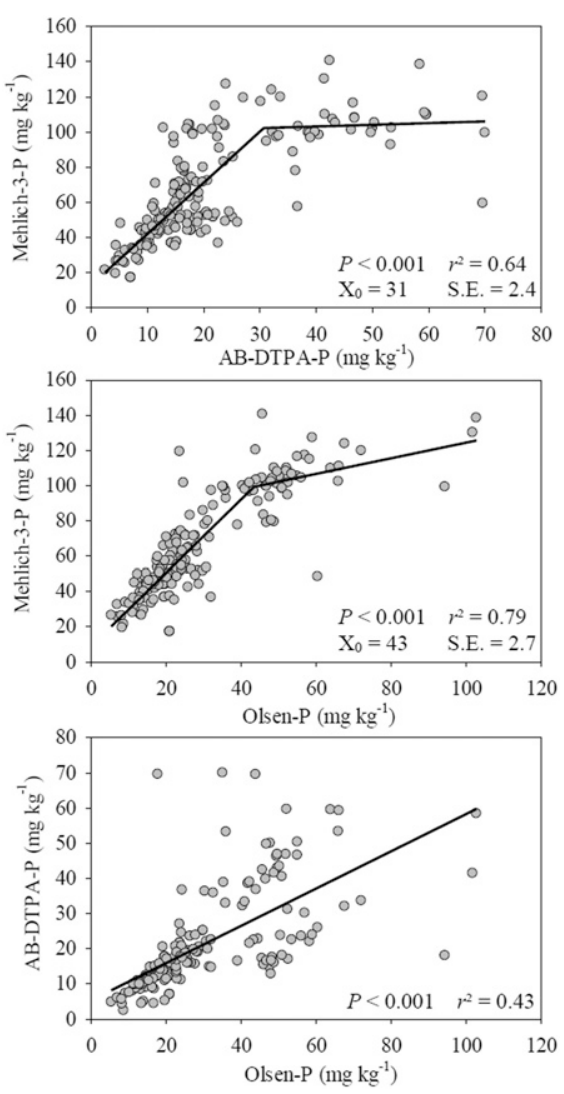

Fig. 1. Correlation of soil-test phosphorus (P) concentrations extracted by Mehlich-3, ammonium bicarbonate-diethylenetriaminepentaacetic acid (AB-DTPA), and Olsen. Number of data points was $180(6$ treatments $\times 3$ replications $\times 5$ sampling dates $\times 2$ seasons). $X_{0}$, change point of soil-test P; S.E., standard error for the change point.

All three multiple regression models regressing relative yield against STP and $\mathrm{P}$ rate were significant (Table 3; Fig. 2). These models predicted that $50 \%$ relative yield would be produced at a $\mathrm{P}$ rate of $0 \mathrm{~kg} \cdot \mathrm{ha}^{-1}$ and 42,13 , and $19 \mathrm{mg} \cdot \mathrm{kg}^{-1}$ of Mehlich-3-P,
AB-DTPA-P, and Olsen-P, respectively. Mehlich-3-P and Olsen-P were 76 and 24 $\mathrm{mg} \cdot \mathrm{kg}^{-1}$, respectively, when $75 \%$ relative yield was predicted without $\mathrm{P}$ fertilization. The $90 \%$ relative yield was predicted without $P$ fertilization when Mehlich-3-P and Olsen$\mathrm{P}$ were 89 and $26 \mathrm{mg} \cdot \mathrm{kg}^{-1}$, respectively. The model using AB-DTPA-P could not predict relative yield $\geq 75 \%$ with a $\mathrm{P}$ rate of $0 \mathrm{~kg} \cdot \mathrm{ha}^{-1}$. $\mathrm{P}$ rates of 138 and $52 \mathrm{~kg} \cdot \mathrm{ha}^{-1}$ were required to produce $90 \%$ relative yield for soils with 42 and $76 \mathrm{mg} \cdot \mathrm{kg}^{-1}$ Mehlich-3-P, respectively. Adopting the $\mathrm{P}$ index threshold of 150 , when Mehlich$3-\mathrm{P}$ concentrations were 42 and $76 \mathrm{mg} \cdot \mathrm{kg}^{-1}$, the $\mathrm{P}$ rate should not exceed 112 and $95 \mathrm{~kg} \cdot \mathrm{ha}^{-1}$, respectively. The required $P$ rates were 176 and $60 \mathrm{~kg} \cdot \mathrm{ha}^{-1}$ to produce $90 \%$ relative yield when Olsen-P was 19 and $24 \mathrm{mg} \cdot \mathrm{kg}^{-1}$, respectively, whereas $136 \mathrm{~kg} \cdot \mathrm{ha}^{-1}$ was predicted for soils having $13 \mathrm{mg} \cdot \mathrm{kg}^{-1}$ AB-DTPA-P.

Significant responses of water-P and leachate DRP to the STP concentrations were detected for all the three extractants (Figs. 3 and 4). The relationship between water-P and Mehlich-3-P was described by a split-line model, and a change point of $88 \mathrm{mg} \cdot \mathrm{kg}^{-1}$ was predicted (Fig. 3). The split-line model using AB-DTPA-P had the lowest $r^{2}$ value and could not yield a reasonable change point. Nonetheless, a change point of $26 \mathrm{mg} \cdot \mathrm{kg}^{-1}$ was predicted from the relationship between water-P and Olsen-P. In the correlations with leachate DRP, the greatest $r^{2}$ value was observed using Mehlich-3-P (Fig. 4). A split-line model with a change point of 104 $\mathrm{mg} \cdot \mathrm{kg}^{-1}$ predicted the response of leachate DRP to Mehlich-3-P, whereas simple linear models predicted the responses of leachate DRP to AB-DTPA-P and Olsen-P. In the simple linear models, the $\mathrm{x}$-intercepts of 7 and $10 \mathrm{mg} \cdot \mathrm{kg}^{-1}$ were the change points for AB-DTPA-P and Olsen-P, respectively.

\section{Discussion}

Correlations among STP. The amounts of $\mathrm{P}$ extracted by Mehlich-3 were greater than the amounts extracted by AB-DTPA and Olsen, demonstrating that the hydrogen ion $\left(\mathrm{H}^{+}\right)$plus $\mathrm{F}^{-}$in Mehlich-3 were more effective in releasing $\mathrm{P}$ than $\mathrm{HCO}_{3}^{-}$(Elrashidi et al., 2001). Furthermore, the efficiency of $P$ extraction by $\mathrm{HCO}_{3}{ }^{-}$decreased with increasing $\mathrm{P}$ rates, as indicated by Castro and Torrent (1995). Although a similar chemical mechanism was followed to extract $\mathrm{P}$ by $\mathrm{AB}-$ DTPA and Olsen, the greatest correlation was observed between Mehlich-3-P and Olsen-P. This result was probably attributed to the low solution-to-soil ratio $(2: 1)$ in the AB-DTPA extraction procedure.

In the relationship between Mehlich-3-P and Olsen-P, the slope of the correlation line declined significantly when Mehlich-3-P was greater than $99 \mathrm{mg} \cdot \mathrm{kg}^{-1}$. Nevertheless, a simple linear relationship was found in previous studies except for the work of Kumaragamage et al. (2007), who showed the slope of the correlation line decreased from 2.3 to 1.6 when extending the Olsen-P concentrations from 100 to $352 \mathrm{mg} \cdot \mathrm{kg}^{-1}$. The decreased slope was probably attributed to the reduced activity of $\mathrm{H}^{+}$and $\mathrm{F}^{-}$in the Mehlich-3 solution through neutralization and precipitation. Different from our study, the simple linear relationship between Mehlich-3-P and Olsen$\mathrm{P}$ occurred in soils with either less than 195 $\mathrm{g} \cdot \mathrm{kg}^{-1}$ carbonate content (Ebeling et al., 2008; Mallarino, 1997; Pizzeghello et al., 2016; Sen Tran et al., 1990) or less than 40 $\mathrm{mg} \cdot \mathrm{kg}^{-1}$ Mehlich-3-P (Iatrou et al., 2014). Thus, both $\mathrm{CaCO}_{3}$ and $\mathrm{P}$ contents should be taken into consideration when determining the relationship between $\mathrm{P}$ extractants in calcareous soils.

Critical level of STP. From an agronomic perspective, the concentration of STP extracted by an effective extractant should correlate sufficiently with crop response. Havlin et al. (2005) showed the crop response to soil-P nutrition usually occurred during early plant growth stages. In addition, the extra-large and large tomatoes, which brought greater returns to growers than 
Table 3. Regression coefficient of multiple regression models using tomato relative yield (measured as a percentage) regressed against preplant soil-test phosphorus (P) (STP; measured in milligrams per kilogram) and P fertilizer application rate (PR; measured in kilograms per hectare).

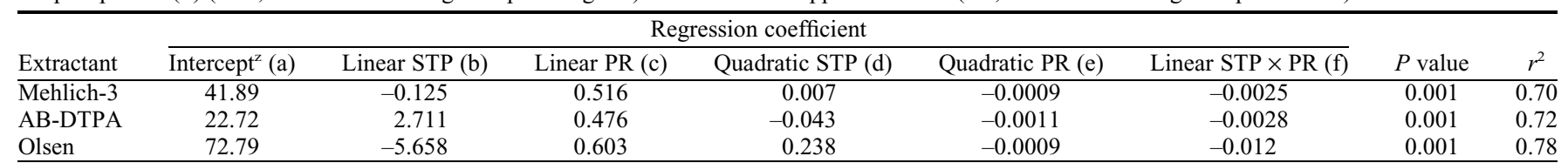

${ }^{\mathrm{z}}$ Equation of the model: Relative yield $=\mathrm{a}+(\mathrm{b} \times \mathrm{STP})+(\mathrm{c} \times \mathrm{PR})+\left(\mathrm{d} \times \mathrm{STP}^{2}\right)+\left(\mathrm{e} \times \mathrm{PR}^{2}\right)+(\mathrm{f} \times \mathrm{STP} \times \mathrm{PR})$.

$r^{2}=$ coefficient of determination; AB-DTPA = ammonium bicarbonate-diethylenetriaminepentaacetic acid.
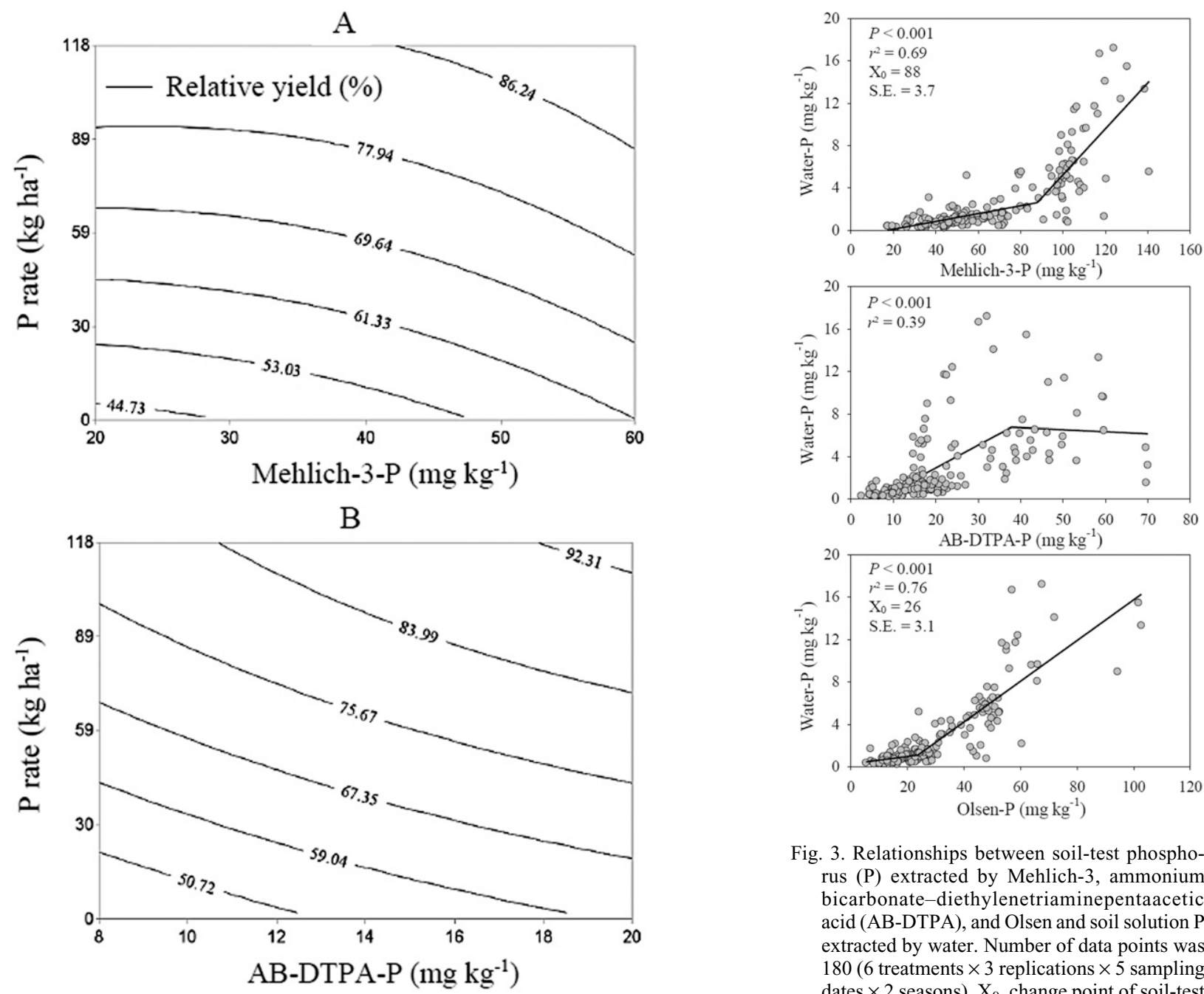

Fig. 3. Relationships between soil-test phosphorus (P) extracted by Mehlich-3, ammonium bicarbonate-diethylenetriaminepentaacetic acid (AB-DTPA), and Olsen and soil solution P extracted by water. Number of data points was 180 ( 6 treatments $\times 3$ replications $\times 5$ sampling dates $\times 2$ seasons). $\mathrm{X}_{0}$, change point of soil-test P; S.E., standard error for the change point.

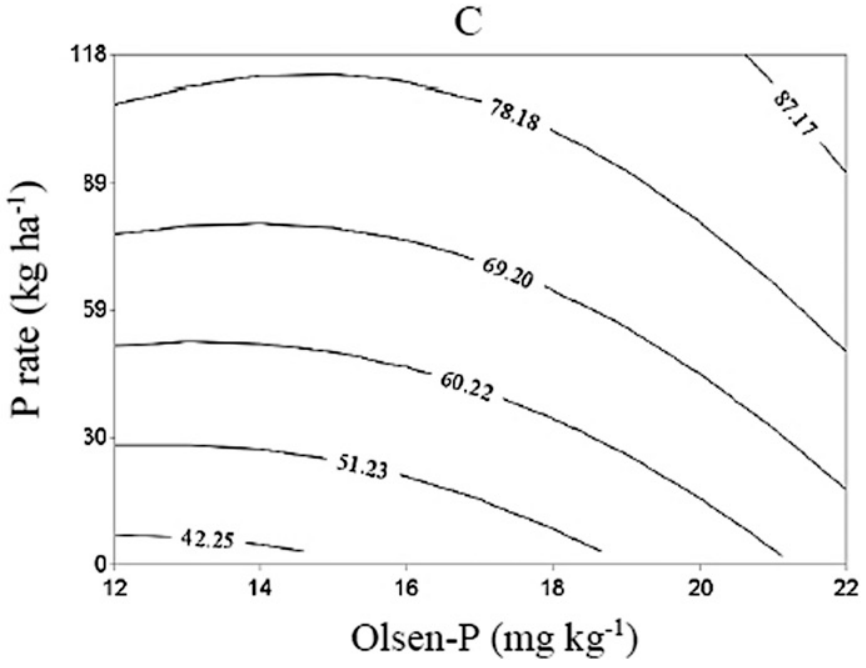

Fig. 2. Tomato relative yield as estimated by multiple regression models using phosphorus (P) fertilizer application rates and preplant soil-test P extracted by (A) Mehlich-3, (B) ammonium bicarbonatediethylenetriaminepentaacetic acid (AB-DTPA), and (C) Olsen.

medium-size fruit, were mainly from the first and second harvests (Zhu et al., 2017a). As a result, the significantly affected tomato marketable yields from FH in 2014 and FSH in 2015 were selected to regress against STP. In 2015, the tomato yields of FSH, rather than $\mathrm{FH}$, were used because of the relatively low proportion $(13 \%$ to $54 \%)$ of $\mathrm{FH}$ in $\mathrm{TSH}$ yields. Ussiri et al. (1998) found ABDTPA-P obtained a greater correlation with corn (Zea mays L.) relative yield than Mehlich-3-P in soils with a $\mathrm{pH}$ level ranging from 4.8 to 7.7 . In our study, although the $r^{2}$ values of the multiple regression models using Olsen-P and AB-DTPA-P were slightly greater than that of Mehlich-3-P, all three models were significant. According to the calibration models, the critical level of ABDTPA-P for producing $90 \%$ relative yield could not be predicted, and a more reasonable 

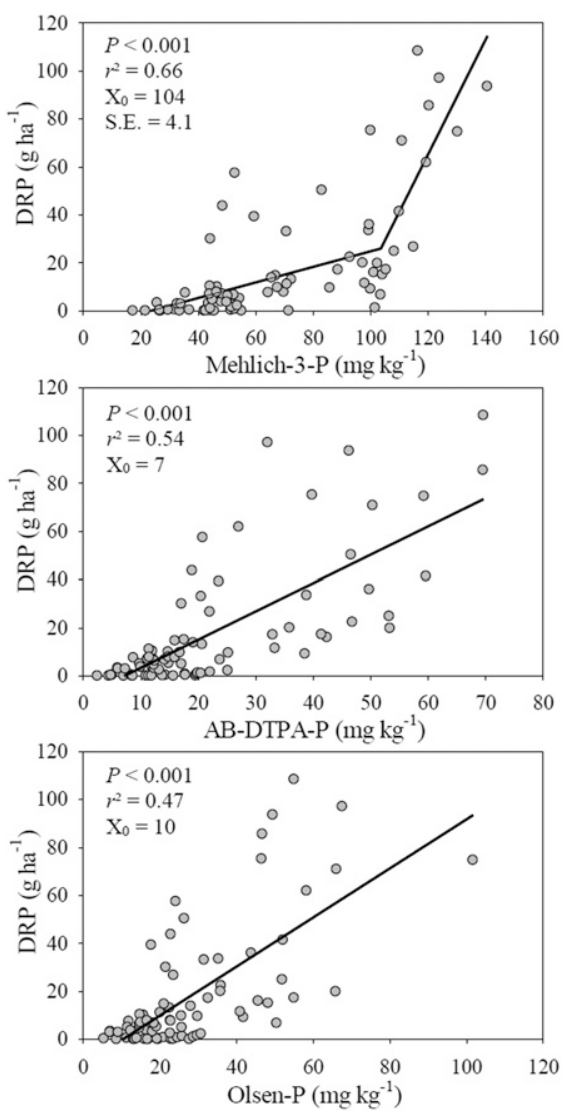

Fig. 4. Relationships between soil-test phosphorus (P) extracted by Mehlich-3, ammonium bicarbonate-diethylenetriaminepentaacetic acid (AB-DTPA), and Olsen and dissolved reactive $P(D R P)$ in leachate. Number of data points was 78 [ $(4$ treatments $\times 3$ sampling dates +1 treatments $\times 1$ sampling date) $\times 3$ replications $\times 2$ seasons]. $X_{0}$, change point of soil-test P; S.E., standard error for the change point.

medium level was identified by Mehlich-3-P, which was from 76 to $89 \mathrm{mg} \cdot \mathrm{kg}^{-1}$.

When correlating with water-P, Mehlich3-P and Olsen-P resulted in similar $r^{2}$ values in the split-line models, which was consistent with the observations of Pizzeghello et al. (2016). Meanwhile, the split-line model using Mehlich-3-P explained the greatest variability $(66 \%)$ of leachate DRP. The change points were predicted to be 88 or $104 \mathrm{mg} \cdot \mathrm{kg}^{-1}$ Mehlich-3-P and 10 or $26 \mathrm{mg} \cdot \mathrm{kg}^{-1}$ Olsen-P in our study. In calcareous soils, the change points of $100 \mathrm{mg} \cdot \mathrm{kg}^{-1}$ Mehlich-3-P and 40 to $60 \mathrm{mg} \cdot \mathrm{kg}^{-1}$ Olsen-P have been reported previously (Bai et al., 2013; Ige et al., 2006; Pizzeghello et al., 2016). The different results might be a result of different soil-P sorption capacities (Hesketh and Brookes, 2000) or the $\mathrm{P}$ fertilizer-amended soils used in our study. Overall, $89 \mathrm{mg} \cdot \mathrm{kg}^{-1}$ Mehlich-3-P could be considered the critical value to distinguish medium and high levels according to both crop response and the environmental risk assessment. This value was greater than the related one $\left(45 \mathrm{mg} \cdot \mathrm{kg}^{-1}\right)$ in acid-mineral soils in Florida (Freeman et al., 2014b), which might be attributed to the greater $\mathrm{P}$ fixation effect in the studied calcareous soils.
Phosphorus application rate recommendation. Calculated from the multiple regression models, the very low STP level was predicted to be less than 42,13 , and $19 \mathrm{mg} \cdot \mathrm{kg}^{-1}$ Mehlich-3-P, AB-DTPA-P, and Olsen-P, respectively. At these critical concentrations, the calculated $\mathrm{P}$ requirement using Olsen-P was about $40 \mathrm{~kg} \cdot \mathrm{ha}^{-1}$ greater than the other two extractants. The recommended $\mathrm{P}$ rate was only $73 \mathrm{~kg} \cdot \mathrm{ha}^{-1}$ for tomato production on acid-mineral soils with low STP levels in Florida (Freeman et al., 2014b). In addition, Zhang et al. (2007) recommended $55 \mathrm{~kg} \cdot \mathrm{ha}^{-1}$ for tomato production in calcareous soils with less than $50 \mathrm{mg} \cdot \mathrm{kg}^{-1}$ Olsen-P. Thus, the proposed $\mathrm{P}$ rate of 176 $\mathrm{kg} \cdot \mathrm{ha}^{-1}$ through Olsen-P seemed to be impractical. Lower and similar $\mathrm{P}$ rates were predicted from the multiple regression models for the very low level of Mehlich-3$\mathrm{P}$ and AB-DTPA-P. However, the rate of 138 $\mathrm{kg} \cdot \mathrm{ha}^{-1}$ predicted from Mehlich-3-P was still greater than the maximum input $\left(112 \mathrm{~kg} \cdot \mathrm{ha}^{-1}\right)$ according to the threshold of the $\mathrm{P}$ index. As a consequence, $112 \mathrm{~kg} \cdot \mathrm{ha}^{-1}$ was selected as the recommendation when Mehlich-3-P was 42 $\mathrm{mg} \cdot \mathrm{kg}^{-1}$. At the medium STP level, the predicted $\mathrm{P}$ rate $\left(52 \mathrm{~kg} \cdot \mathrm{ha}^{-1}\right)$ by Mehlich-3$\mathrm{P}$ was similar to the proposed amount $(60$ $\mathrm{kg} \cdot \mathrm{ha}^{-1}$ ) using Olsen-P and less than the ceiling amount $\left(95 \mathrm{~kg} \cdot \mathrm{ha}^{-1}\right)$ calculated from the $\mathrm{P}$ index.

\section{Conclusions}

Compared with AB-DTPA, Mehlich-3 resulted in a greater correlation with Olsen in testing P availability. A very low STP level was predicted of less than 42, 13, and 19 $\mathrm{mg} \cdot \mathrm{kg}^{-1}$ by the multiple regression models using Mehlich-3-P, AB-DTPA-P, and Olsen$\mathrm{P}$, respectively. The high level of Mehlich-3$\mathrm{P}$ was estimated to be more than $89 \mathrm{mg} \cdot \mathrm{kg}^{-1}$ considering both agronomic and environmental impacts, whereas the regression model using AB-DTPA-P could not predict this critical value. The required $\mathrm{P}$ amounts were predicted from 52 to $112 \mathrm{~kg} \cdot \mathrm{ha}^{-1}$ when Mehlich-3-P ranged from 76 to $42 \mathrm{mg} \cdot \mathrm{kg}^{-1}$. The calibration approach using Olsen-P could not propose a practical $\mathrm{P}$ application rate for the low STP levels. Therefore, Mehlich-3 can be considered the most effective extractant to assess $\mathrm{P}$ availability and calibrate $\mathrm{P}$ rates for tomato production on the calcareous soils in Florida.

\section{Literature Cited}

Bai, Z., H. Li, X. Yang, B. Zhou, X. Shi, B. Wang, D. Li, J. Shen, Q. Chen, W. Qin, O. Oenema, and F. Zhang. 2013. The critical soil P levels for crop yield, soil fertility and environmental safety in different soil types. Plant Soil 372: 27-37.

Castro, B. and J. Torrent. 1995. Phosphate availability in calcareous Vertisols and Inceptisols in relation to fertilizer type and soil properties. Fert. Res. 40:109-119.

Ebeling, A.M., L.G. Bundy, A.W. Kittell, and D.D. Ebeling. 2008. Evaluating the Bray P1 test on alkaline, calcareous soils. Soil Sci. Soc. Amer. J. 72:985-991.
Elrashidi, M.A., A.K. Alva, Y.F. Huang, D.V. Calvert, T.A. Obreza, and Z.L. He. 2001. Accumulation and downward transport of phosphorus in Florida soils and relationship to water quality. Commun. Soil Sci. Plant Anal. 32:3099-3119.

Florida Administrative Code. 2017. Rule 62-302.540. Water quality standards for phosphorus within the Everglades Protection Area, Tallahassee, FL. 30 May 2017. <https://www.flrules.org/gateway/ RuleNo.asp?ID=62-302.540>.

Freeman, J.H., E.J. McAvoy, N. Boyd, P.J. Dittmar, M. Ozores-Hampton, H.A. Smith, G.E. Vallad, and S.E. Webb. 2014a. Tomato production, p. 183-204. In: G.E. Vallad, J.H. Freeman, and P.J. Dittmar (eds.). 2014-2015 Vegetable and small fruit production handbook of Florida. Vance Publishers, Lenexa, KS.

Freeman, J.H., G.E. Vallad, G. Liu, E.H. Simonne, G.J. Hochmuth, M.D. Dukes, L. Zotarelli, J.W. Noling, D.A. Botts, P.J. Dittmar, and S.A. Smith. 2014b. Vegetable production in Florida, p. 1-6. In: G.E. Vallad, J.H. Freeman, and P.J. Dittmar (eds.). 2014-2015 Vegetable and small fruit production handbook of Florida. Vance Publishers, Lenexa, KS.

Havlin, J.L., J.D. Beaton, S.L. Tisdale, and W.L. Nelson. 2005. Phosphorus, p. 160-198. In: Soil fertility and fertilizers: An introduction to nutrient management. Pearson Education Inc., Upper Saddle River, NJ.

Hesketh, N. and P.C. Brookes. 2000. Development of an indicator for risk of phosphorus leaching. J. Environ. Qual. 29:105-110.

Hurt, G.W., R.S. Mylavarapu, and S.P. Boetger. 2013. UF/IFAS nutrient management series: Computational tools for field implementation of the Florida phosphorus index: Dade County Florida. Univ. Florida, Inst. Food Agr. Sci., Electronic Data Info. Source. 20 Sept. 2017. $<$ http://edis.ifas.ufl.edu/ss371>.

Iatrou, M., A. Papadopoulos, F. Papadopoulos, O. Dichala, P. Psoma, and A. Bountla. 2014. Determination of soil available phosphorus using the Olsen and Mehlich 3 methods for Greek soils having variable amounts of calcium carbonate. Commun. Soil Sci. Plant Anal. 45:2207-2214.

Ige, D.V., O.O. Akinremi, D. Flaten, and M.A. Kashem. 2006. Comparison of soil test phosphorus methods in neutral to calcareous Manitoba soils. Can. J. Soil Sci. 86:691-699.

Korndorfer, G.H., D.L. Anderson, K.M. Portier, and E.A. Hanlon. 1995. Phosphorus soil test correlation to sugarcane grown on Histosols in the Everglades. Soil Sci. Soc. Amer. J. 59:1655-1661.

Kumaragamage, D., O.O. Akinremi, D. Flaten, and J. Heard. 2007. Agronomic and environmental soil test phosphorus in manured and nonmanured Manitoba soils. Can. J. Soil Sci. $87: 73-83$.

Lemunyon, J.L. and R.G. Gilbert. 1993. The concept and need for a phosphorus assessment tool. J. Prod. Agr. 6:483-486.

Li, Y.C., S. O'Hair, R. Mylavarapu, T. Olczyk, and M. Lamberts. 2000. Demonstration of phosphorus fertilizer management for potato grown in a calcareous soil. Proc. Annu. Mtg. Fla. State Hort. Soc. 113:237-239.

Mallarino, A.P. 1997. Interpretation of soil phosphorus tests for corn in soils with varying $\mathrm{pH}$ and calcium carbonate content. J. Prod. Agr. 10:163-167.

McDowell, R.W. and A.N. Sharpley. 2001. Phosphorus losses in subsurface flow before and after manure application to intensively farmed land. Sci. Total Environ. 278:113-125. 
McDowell, R., A. Sharpley, P. Brookes, and P. Poulton. 2001. Relationship between soil test phosphorus and phosphorus release to solution. Soil Sci. 166:137-149.

Mehlich, A. 1984. Mehlich 3 soil test extractant: A modification of Mehlich 2 extractant. Commun. Soil Sci. Plant Anal. 15:1409-1416.

Mengel, K. and E.A. Kirkby. 1987. Phosphorus, p. 403-420. In: Principles of plant nutrition. International Potash Institute, Bern, Switzerland.

Murphy, J. and J.R. Riley. 1962. A modified single solution method for the determination of phosphate in natural waters. Anal. Chim. Acta 27:31-36.

Olsen, S.R., C.V. Cole, F.S. Watanabe, and L.A. Dean. 1954. Estimation of available phosphorus in soils by extraction with sodium bicarbonate. U.S. Department of Agriculture circular 939. U.S. Government Printing Office, Washington, DC.

Pizzeghello, D., A. Berti, S. Nardi, and F. Morari. 2016. Relationship between soil test phosphorus and phosphorus release to solution in three soils after long-term mineral and manure application. Agr. Ecosyst. Environ. 233:214-223.

Rashid, A., J. Din, and M. Bashir. 1999. Phosphorus deficiency diagnosis and fertilization in mungbean grown in rainfed calcareous soils of Pakistan. Commun. Soil Sci. Plant Anal. 30:2045-2056.

Savoy, H.J. 2013. Procedures used by state soil testing laboratories in the southern region of the United State. Clemson University. 16 June 2017. <http://aesl.ces.uga.edu/sera6/PUB/ 409June2013CUPDATE.asp>.
Sen Tran, T., M. Giroux, J. Guilbeault, and P. Audesse. 1990. Evaluation of Mehlich-III extractant to estimate the available P in Quebec soils. Commun. Soil Sci. Plant Anal. 21:1-28.

Sims, J.T., R.O. Maguire, A.B. Leytem, K.L. Gartley, and M.C. Paulter. 2002. Evaluation of Mehlich 3 as an agri-environmental soil phosphorus test for the Mid-Atlantic United States of America. Soil Sci. Soc. Amer. J. 66:2016-2032.

Slaton, N.A., B.R. Golden, R.J. Norman, C.E. Wilson, Jr., and R.E. DeLong. 2009. Correlation and calibration of soil potassium availability with rice yield and nutritional status. Soil Sci. Soc. Amer. J. 73:1192-1201.

Soltanpour, P.N. and A.P. Schwab. 1977. A new soil test for simultaneous extraction of macroand micro-nutrients in alkaline soils. Commun. Soil Sci. Plant Anal. 8:195-207.

U.S. Department of Agriculture. 1996. Soil survey of Dade County area, Florida. U.S. Department of Agriculture, Natural Resources Conservation Service. Washington, DC. 30 May 2016. <https://www.nrcs.usda.gov/Internet/ FSE_MANUSCRIPTS/florida/FL686/0/Dade. pdf $>$.

U.S. Department of Agriculture. 2014. 2012 Census county-level data, Florida. U.S. Department of Agriculture, Census of Agriculture, Washington, DC. 7 Oct. 2016. <https://www. agcensus.usda.gov/Publications/2012/Full_ Report/Volume_1,_Chapter_2_County_Level/ Florida/st12_2_029_029.pdf $>$.

Ussiri, D.A., P.N.S. Mnkeni, A.F. MacKenzie, and J.M.R. Semoka. 1998. Soil test calibration studies for formulation of phosphorus fertilizer recommendations for maize in Morogoro district, Tanzania: I. Evaluation of soil test methods. Commun. Soil Sci. Plant Anal. 29:2801-2813.

von Wandruszka, R. 2006. Phosphorus retention in calcareous soils and the effect of organic matter on its mobility. Geochem. Trans. 7:6-14.

Wang, J.J., D.L. Harrell, R.E. Henderson, and P.F. Bell. 2004. Comparison of soil-test extractants for phosphorus, potassium, calcium, magnesium, sodium, zinc, copper, manganese, and iron in Louisiana soils. Commun. Soil Sci. Plant Anal. 35:145-160.

Zhang, X.S., H. Liao, Q. Chen, P. Christie, X.L. Li, and F.S. Zhang. 2007. Response of tomato on calcareous soils to different seedbed phosphorus application rates. Pedosphere 17:70-76.

Zhu, Q., M. Ozores-Hampton, and Y. Li. 2016. Comparison of Mehlich-3 and ammonium bicarbonate-DTPA for the extraction of phosphorus and potassium in calcareous soils from Florida. Commun. Soil Sci. Plant Anal. 47:2315-2324.

Zhu, Q., M. Ozores-Hampton, Y. Li, K. Morgan, G. Liu, and R.S. Mylavarapu. 2017a. Effect of phosphorus rates on growth, yield, and postharvest quality of tomato in a calcareous soil. HortScience 52:1406-1412.

Zhu, Q., M. Ozores-Hampton, Y.C. Li, and R.S. Mylavarapu. 2017b. Comparing extractants for calibrating potassium rates for tomato grown on a calcareous soil. Soil Sci. Soc. Amer. J. 81:1621-1628. 